
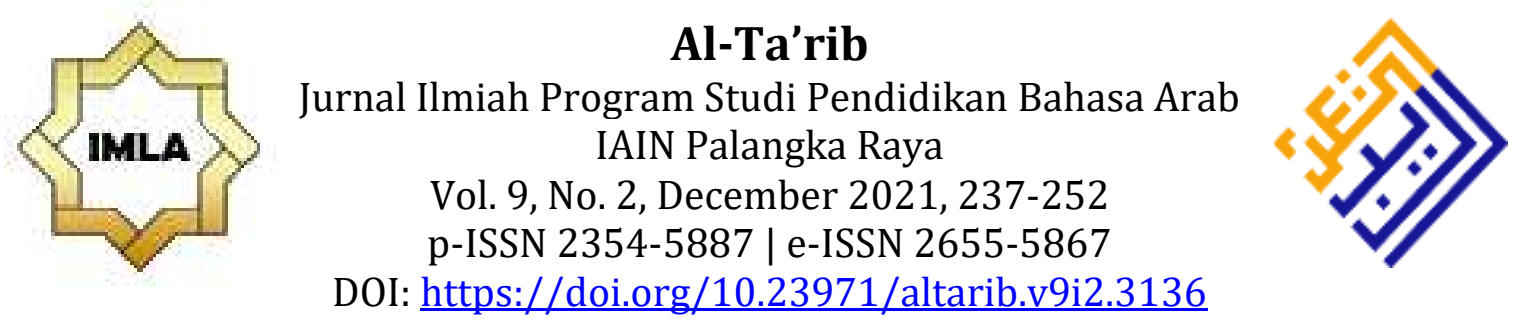

\title{
RELATIONSHIP BETWEEN SELF-REGULATED LEARNING AND READING SKILLS ABILITY FOR ARABIC LANGUAGE AND LITERATURE STUDY PROGRAM STUDENTS IN EAST JAVA
}

\author{
العلاقة بين التعلم المنظم ذاتيا ومهارة القراءة لدى طلاب قسم اللغة العربية وآدابها بجاوى الشرقية
}

\author{
Lailatul Qomariyah', Usfiyatur Rusuly², Ade Destri Deviana ${ }^{3}$ \\ ${ }^{1}$ Universitas Hasyim Asy'ari Tebuireng Jombang, Indonesia \\ 2Universitas Islam Negeri Maulana Malik Ibrahim Malang, Indonesia \\ ${ }^{3}$ STIQ Amuntai Kalimatan Selatan, Indonesia \\ E-mail: lailatulqomariyah.unhasy@gmail.com
}

\begin{abstract}
Reading skills require Self-Regulated Learning (SRL) in student which is very important to achieve success in this competency. With SRL, students will know what strategies they must do to achieve these competencies. The purpose of this article is to reveal: 1) Correlation between Self-Regulated Learning with student reading skills. This article used quantitative method. The study sample consisted of 168 students of the Arabic Language Study Program and Literature in Malang. The research data was obtained from questionnaire, and test. The quantitative data analysis method uses Pearson correlation analysis. The results showed that there was a correlation between Self-Regulated Learning and reading skills with a correlation coefficient category of 0.357 which was categorized as strong enough. The results of the SelfRegulated Learning variable indicate that implementing aspect is the dominant aspect that can be seen. Of the highest loading factor value. The results of this study provide input for Arabic language teachers to train their students to think critically in reading activities so that they are motivated to have independence in producing messages from reading.
\end{abstract}

Keywords: Reading Skill, Self Regulated Learning, implementing aspect

\section{Abstrak}

Kemahiran membaca membutuhkan Self-Regulated Learning (SRL) yang baik dalam diri siswa yang mana kedudukannya sangat penting untuk mencapai keberhasilan pada kompetensi ini. Dengan SRL, mahasiswa akan mengetahui strategi apa yang harus dilakukannya untuk mencapai kompetensi tersebut. Tujuan penelitian ini untuk mengungkap korelasi antara Self-Regulated Learning dengan kemahiran membaca mahasiswa. Penelitian ini menggunakan metode penelitian kuantitatif. Sampel penelitian terdiri dari 168 mahasiswa prodi Bahasa dan Sastra Arab di Malang. Data penelitian diperoleh dari angket yang digunakan untuk mengetahui data SRL mahasiswa dan tes untuk memperoleh data kemahiran 
membacanya. Metode analisis data kuantitatif menggunakan analisis korelasi Pearson. Hasil penelitian menunjukkan bahwa terdapat korelasi antara SelfRegulated Learning dengan kemahiran membaca pada kategori koefisien korelasi sebesar 0,357 yang masuk dalam kategori cukup kuat. Hasil dari variabel SelfRegulated Learning menunjukkan bahwa aspek implementasi merupakan aspek dominan yang dapat dilihat dari nilai loading factor tertinggi. Hasil penelitian ini memberikan masukan bagi pendidik Bahasa Arab untuk melatih peserta didiknya agar berpikir kritis dalam kegiatan membaca sehingga dia termotivasi untuk memiliki kemandirian dalam memproduksi pesan dari bacaan.

Kata kunci: Kemahiran membaca, Self-Regulated Learning, aspek implementasi

المقدمة

التعليم هو ثقافة ديناميكية، تم تطويرها وبناؤها من الثقافات القائمة وعلى أساس نظرية أنتجت

في السابق. من هنا الحاجة إلى بناء نموذج جديد. تغيير نموذج التعليم المدروس (تعليم يركز على المعلم) إلى تعليم يركز على المتعلم. واحدة من الجهود الهامة في تحسين عملية التعلم هي زيادة تعلم المتعلمين النشطين. ستنعكس التغييرات التي طرأت على السؤال في أنشطة التعلم التي تعطي المتعلمين مسؤولية كبيرة عن طريقة تعلمهم. سوف تكون أنشطة التعلم ذات معنى في حياهم، بمعنى أن المتعلمين قادرين على تطوير أنفسهم بما في ذلك تعلم المعرفة وتعلّم القيام بها وتعلم أن تكون وتعلّم العيش معاً كما أوصت به يونسكو UNESCO وهذه الحالة كما قدمت سوتكنو (Sutikno, 2015) في كتابه.

والعامل الذي يؤثر على نتائج التعلم هو التعلم المنظم ذاتيا. التعلم المنظم ذاتيا هو حالة التعلم

حيث يملك الطلبة في عملية التعلم من خلال المعرفة وتطبيق الاستراتيجيات المناسبة، وفهم وظيفتهم، وتقوية في عملية صنع القرار ودوافع التعلم. يقول زيمرمان ومارتينيز بونز أن التعلم المنظم ذاتيًا هو مفهوم كيف يصبح الطالب منظمًا لتعلمه الخاص (Zimmerman \& Martinez-Pons, 1990). أن التعلم في ضوء التعلم المنظم ذاتيا عملية المستقلة من الطلبة ذاتيا في تحديد أهداف التعلم والتوجيه والإشراف والتنظيم (Zimmerman, 2002). التعلم المنظم ذاتيا للطلاب هو القدرة التي تتجلى في كيفية تنظيم التعلم. إن طريقة تنظيم التعلم التي يحتاج الطلبة إلى أخذها في الاعتبار هي الجمع بين القدرات الفكرية للمعرفة والمحتوى ذي الصلة من خلال المهارات المعرفية واستراتيجيات المكافحة وسلوك الفرد. وأكد يولاند (Yulanda, 2017)

وبالتالي، يتم تطبيق نجاح أو فشل كيفية تنظيم التعلم على الطلبة، وهذا يتوقف على مدى تطبيق الطلبة لكيفية تنظيم التعلم وفقًا للإمكانيات المتوفرة لديه. وجدت الدراسة أن الطلبة الذين يديرون أنفسهم بنشاط في التعلم يميلون إلى الحصول على نتائج تعليمية أفضل في المجال الأكاديمي (Zahary, 2015). التعلم المنظم ذاتيا هو الجههد طالب واعي في إدارة الأشياء المتعلقة بالتعلم بشكل المستقل. وتحقيق نجاح 
تعلم الطلبة من خلال التعلم المنظم ذاتيا في تعلم الجيد. كلما يكون الطلبة أكثر قدرة على التنظيم تعلمهم، سيكون الطلبة أن يستطيعوا قدرتم على تحقيق الأهداف المرجوه وقال سنتروك "أن الطلبة عالية وغالبة هم يكونون في التنظيم تعلمهم". إذان التعلم المنظم ذاتيا عند سنتروك (Santrock J, 2008) هو جهد فردي لرصد قدرة الفرد والتخطيط والقيام على الواجبات. دلّ بعض البحوث أن التعلم المنظم ذاتيًا يستطيع أن يؤثر على التحصيل الدراسي لدى الطلبة. ويوضح البحث فيكا ومرلينا (Marlina, 2017; Pratama, 2017) بأن الطلبة القادرين على تمكين الإستراتيجية في التعلم المنظم ذاتيا يجصلون التحصيل الدراسي أفضل من الطلبة غير القادرين على استخدامها. تظهر نتائج إيليانا (Elyana, 2017) أن الطلبة في المدارس الإعدادية غالباً ما يبدون نقصًا في القدرة على تنظيم التعلم مثل عدم قدرة الطلبة على تنظيم الوقت الدراسي بشكل جيد، والكثير من الواجبات المنزلية غير المكتملة، والنتائج السيئة بسبب نقص التعلم مما يؤدي إلى تراجع نتائج التعلم لدى الطلبة وتنمية التفكير الإبداعي لديهم. وبهذه الكفاءة سيشجع الطلبة في قيام العملية التعليمية بأنفسهم وقادر لحل المشكلة التعليمية المصادفة. وهذه موافقة بنظرية عاتوم (Deviana et al., 2019) بأن كفاءة في التفكير الإبداعي هي قادر الشحص في إنتاج حلول المشكلة. بالنسبة إلى أهمية التعلم المنظم ذاتيًا لدى الطلبة في العملية التعليمية وخاصة في تعليم اللغة العربية، فلابد للمعلم أن يكون قادرا على تنمية عادات التعلم لديهم. التعلم الفردي يتضح من وجود التعلم المستقل. وهم لايتعلقون بكون المعلم. وخاصة في تنمية مهارة قراءة العربية لابد عليهم أن يشجع نفسهم لنشط ا دائمًا في قراءة النص وفهم أفكارهم بشكل مستقل. لأن يحتاج هذه المهارة إلى العملية المركبة وهن العقلية والانفعالية والدافعية. وأكد مروان (Marwān, 2012) وعبد الباري في (MĀHIR, 2010) هذه الكفاءة وهي ليس عملية للاستجابات الفسيولوجية على الرموز المكتوبة فقظ بل العملية التي يتطلب فيها من بناء المعنى من خلال تفكير المعنى المضمون، وتحليله، وربطه، واستنتاجه، وتفاعله، ونقده، وتذوقه، وحل المشكلات لهذا المعنى.

وبناء على أهمية هذه الكفاءة لطلاب اللغة خاصة قسم اللغة العربية، لابد لهم أن يحاول تنظيم أنفسهم ليكونوا دائما مشجعين لتعلم اللغة العربية. ووفقا لملاحظة الباحثات، فإن إحدى الجامعات في إندونيسيا التي تحاول دائما تحسين إنجازتا في مجال اللغة العربية هي جامعة مولانا مالك إبراهيم الإسامية الحكومية بمالانج. وهذه الجامعة كقبلة لطلاب الذين يحبون اللغة العربية من جميع أنحاء المدن في إندونيسيا وكذالك الطلاب من عدة الدول الأخرى، وهي سودان، وروسيا، وصومال. 
أثبتت هذه الجامعة أها جامعة رائدة تعمل دائما على تطوير تدريس اللغة العربية في داخل بلاد إندونيسيا وخارجه. لذالك اهتمت الباحثات بالبحث في هذا المكان للحصول على المعلومات المحدثة حول

$$
\text { استراتيجية كيفية تطوير مهارات اللغة العربية. }
$$

هناك عدة البحوث الأخرى الاتي بحثت عن هذا الموضوع التي كتبها الباحثون الأخرون. دراسة التي بحثها عبد الناصر الجراح تحت العنوان العلاقة بين التعلم المنظم ذاتيا والتحصيل الأكاديمي لدى عينة من طلبة جامعة اليرموك. وأهداف هذه الدراسة هي لمعرفة اختلاف التحصيل الأكادمي التي حصل عليه طلاب في المستوى العالي من التعلم المنظم ذاتيا وفي المستوى الأدني. ومنهج لهذا البحث دراسة الارتباطية. وتوصل لباحث بنتائج وهي هناك اختلاف التحصيل الأكاديمي بين طلاب في المستوى العالي من التعلم المنظم ذاتيا وفي المستوى الأدني بنسبة الدلالة الإحصائية. وهذا الاختلاف من ناحية مكوين الأهداف المرجوه، وتخطيطها، وتسميعها، وحفظها ولتصحيح الطلبة في الرتبة لدي التعلم

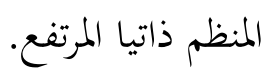

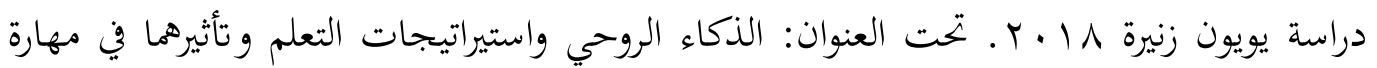
القراءة لدى طلبة قسم تعليم اللغة العربية بالجامعة الإسلامية الحكومية كديري. واستخدمت الباحثة منهج البحث المختلط (Mixed Method) بالتصميم التفسيري المتتابع (Sequential Explanatory Design) وهو عرض البيانات الكمية وتحليلها واستنتاجها أولا ثم البيانات الكيفية وتحليلها واستنتاجها كيفيا. وتوصلت لباحثة بنتائج وهي: (1) أن مستوى الذكاء الروحي لدي الطلاب في مستوى متوسط (Y، Y Y) وأما مستوى كفاءة الطلبة في مهارة القراءة في rا وهي بتقدير درجة مقبول، r) أن الاستراتيجيات الأكثر استخداما في استراتيجية ماوراء المعرفية، ب) توجد فروق ذات دلالة إحصائية بين مستوى الذكاء الروحي ومهارة القراءة، حيث أن الذكاء الروحي العالي يسبب على ارتفاع نتيجة مهارة القراءة وكذلك عكسه، ع) توجد فروق ذات دلالة إحصائية بين استراتيجيات التعلم ومهارة القراءة، خاصة في استراتيجية التأثيرية، ه) كان الذكاء الروحي يؤثر أكثر من استراتيجيات التعلم في مهارات القراءة، 7) إن تطبيق الذكاء الروحي في تعليم مهارة القراءة سوف يكون فعالا إذا أحضر فيه بعد الوعي الإلهي والتفكير النقدي عن موجود. ويفضل الطلبة استراتيجيات التأثيرية لأن المصفاة الوجدانية سيفتح إذاكان جسم الإنسان مسترخيا، وليس قلقا، وليس خوفا، والعقل في حالة قبول، وهذا الحال عندما الذكاء الروحي في حالة عالية. والنتيجة الأساسية ترى على أن التعلم مع وجود الذكاء الروحي والاستراتيجيات التأثيرية يستطيع أن يرقي التحصيل الدراسي. 
دراسة نور المفيدة. تحت العنوان: استراتيجيات التعلم المنظم ذاتيا لمهارة الكتابة لدى طلبة البرنامج

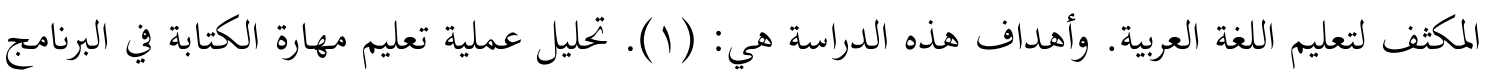

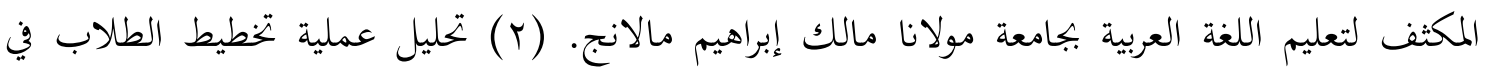

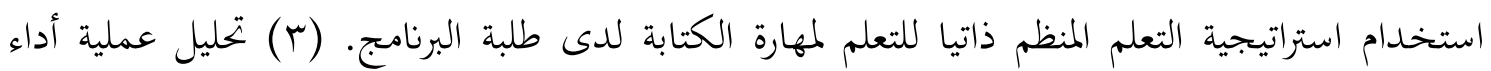

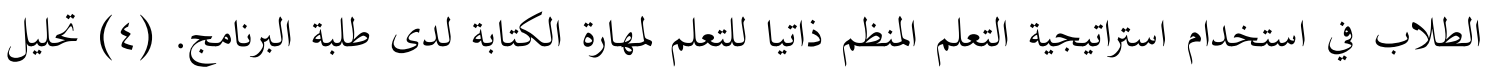
عملية انعكاس الذات (self reflection) عند الطلاب في استخدام استراتيجية التعلم المنظم ذاتيا للتعلم لمهارة الكتابة لدى طلبة البرنامج. واستخدمت الباحثة مدخل البحث المستخدم هو النوعي أو الكيفي.

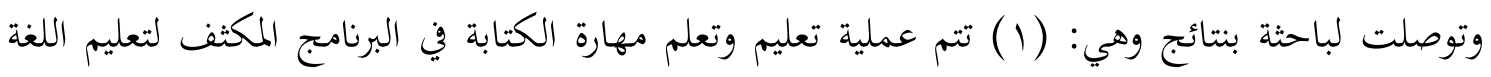
العربية يعنى تقديم المادة والتدريبات يسير كما هو مرتب في الصفحات كتاب العربية بين يديك. وبيانب

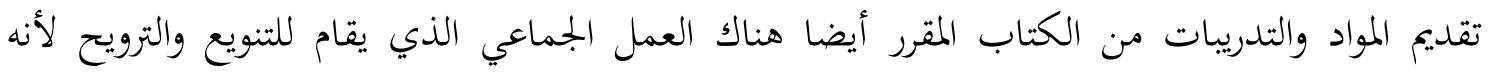

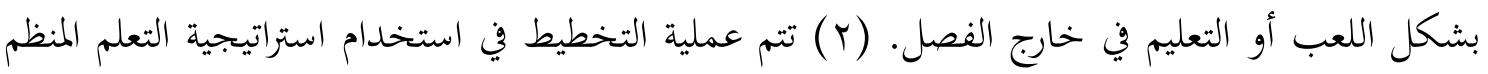

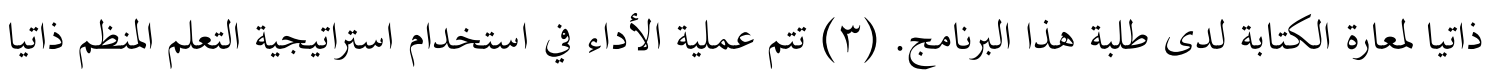

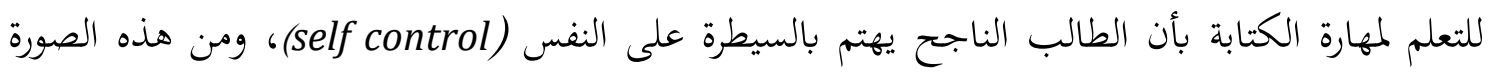

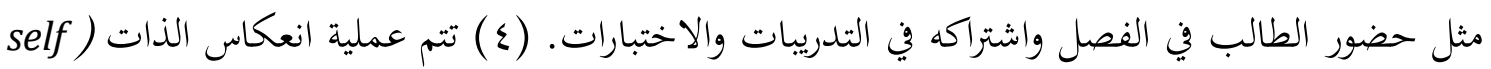
(reflection عند الطلاب في استخدام استراتيجية التعلم المنظم ذاتيا للتعلم لمهارة الكتابة.

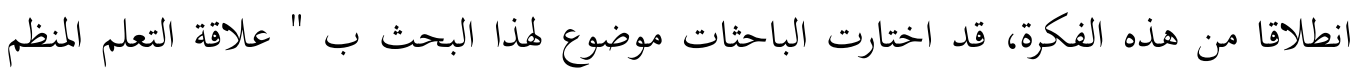
ذاتيا بمهارة القراءة لدى طلبة قسم اللغة العربية وآداهما كلية العلوم الإنسانية بجامعة مولانا مالك إبراهيم

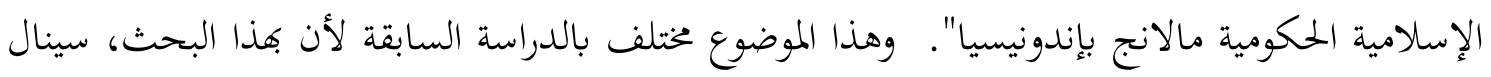
البيانات عن علاقة التعلم المنظم ذاتيا لدى الطلابة بكفائتهم في القراءة.

\section{المنهجية}

المدخل المستخدم لهذا البحث هو كمي. وفي تحديد عدد عنية البحث، عادت الباحثات إلى

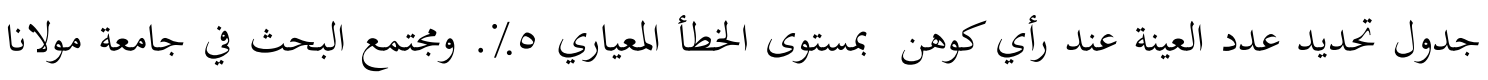

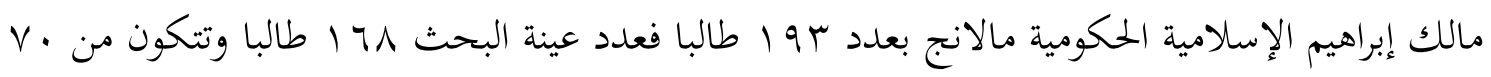
رجلا و 9 نساء. وللحصول على البيانات المحتاجة يعنى لقياس التعلم المنظم ذاتيا لدى طلبة جامعة مولانا مالك

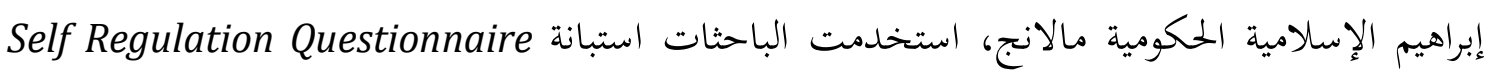


بعدد بنود الإستبانة ب7 بنودا. خلال هذه الاستبانة عرفت الباحثات درجة التعلم المنظم ذاتيا من ناحية الاستعداد التعلم، الإستراتيجيات التعلم. والمقياس المستخدم في هذا الأداة هو مقياس ليكرت (likert) ا-ه. ـ. ولقياس مهارة القراءة قسّمت الباحثات من · ب سؤالا. هذا السؤال هو اختبار قدرة العينة أو الطلاب على فهم النص الأساسي للقراءة. شكل السؤال الذي قدمته الباحثة وهو الاختيار من متعدد بشرط أنه إذا كانت الإجابة الصحيحة تساوي ه، وإذا كانت الإجابة الخاطئة تساوي. . وبذلك تكون أعلى درجة في مهارة القراءة . . ا وأدلى درجة في مهارة القراءة هي . . ولتحليل البيانات الكميية يعني لقياس العلاقة بين المتغيرتين (xy) بحساب الإرتباط بيرسونوفق المعادلة برمز :

$$
r_{x y}=\frac{\sum x y}{\sqrt{\sum^{2} y^{2}}}
$$

\section{نتائج البحث والمناقشة}

علاقة التعلم المنظم ذاتيا بمهارة القراءة لدى طلبة قسم اللغة العربية وآداها كلية العلوم الإنسانية بجامعة مولانا مالك إبراهيم الإسلامية الحكومية مالانج بإندونيسيا عرضتها الباحثات بيانات علاقة التعلم المنظم ذاتيا بمهارة القراءة لدى طلبة قسم اللغة العربية وآداها كلية العلوم الإنسانية جامعة مولانا مالك لـ Self Regulation Questionnaire إبراهيم الإسلامية الحكومية مالانج. استخدمت الباحثات استبانة

.Miller and Brown نتيجة التعلم المنظم ذاتيا بينت الباحثات عن النتيجة العينة في هذا البحث والنتيجة التجربية. لتحدّد القيمة التعلم المنظم ذاتيا لدى الطلاب، انقسمت الباحثات إلى ثلاثة أنواع: المتقدم، المتوسط، المبتدئ. تحديد في هذه القيمة معلوم يتواجد كما يلى:

جدول ا : النتيجة المتوسطة التعلم المنظم ذاتيا

\begin{tabular}{|c|c|c|}
\hline الوسط الحسابي & Mean & المتغير \\
\hline $1 V, 9 r$ & rr.,91 & التعلم المنظم ذاتيا \\
\hline
\end{tabular}

والنتيجة التعلم المنظم ذاتيا:

1. $=X>($ mean + standard deviasi )

$=\mathrm{X}>(220,98+17,92)$

$=\mathrm{X}>239$

1. المتوسط $=($ mean - standard deviasi $) \leq X \leq($ mean + standard deviasi $)$ 


$$
\begin{aligned}
& =(220,98-17,92) \leq X \leq(220,98+17,92) \\
& =203 \leq X \leq 239
\end{aligned}
$$

2. المبتدئ $=X<($ mean - standard deviasi)

$$
=\mathrm{X}<(220,98-17,92)
$$

$=\mathrm{X}<203$

\begin{tabular}{|c|c|c|}
\hline الترتيب & القيمة & التعلم المنظم ذاتيا \\
\hline المتقدم & $X>239$ & \\
\hline المتوسط & $203 \leq X \leq 239$ & \\
\hline المبتدئ & $X<203$ & \\
\hline
\end{tabular}

مستوى العينة التعلم المنظم ذاتيا في هذا البحث كما جدول التالي:

جدول r : القيمة التعلم المنظم ذاتيا على أساس القيمة المتوسطة

انطلاقا من الجدول السابق يدل أن الطلاب يكصل القيمة التعلم المنظم ذاتيا فوق من وبr

يتضمن في الترتيب المتقدم، بينما يكصل القيمة التعلم المنظم ذاتيا بين r · r حتى qجr يتضمن في الترتيب التعلم المنظم ذاتيا المتوسط و الذي لديه التعلم المنظم ذاتيا المبتدئ إذا يكصل تحت ب . r.

\begin{tabular}{|c|c|c|}
\hline درجة مئوية & عدد الطلاب & النتيجة \\
\hline $14,29 \%$ & $r \varepsilon$ & المتقدم \\
\hline $69,64 \%$ & $11 \mathrm{~V}$ & المتوسط \\
\hline $16,07 \%$ & TV & المبتدى \\
\hline $100 \%$ & 171 & العدد \\
\hline
\end{tabular}
أما درجة مئوية الطلاب انطلاقا على النتيجة كما الجدول التالي:

جدول ب: نسبة المستجيبين على أساس مستوى التعلم المنظم ذاتيا

من الجدول السابق يدل أن أكثر من الطلاب لديهم التعلم المنظم ذاتيا في النتيجة المتوسطة يعنى

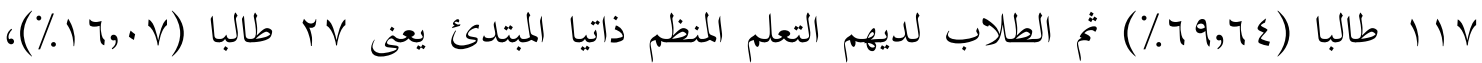

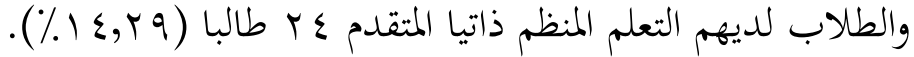
نتائج اختبار الثبات والصدق أدوات البحث للتعلم المنظم ذاتيا النتائج المتعلقة بالسؤال الثاني وهو عن علاقة ذات دلالة احصائية التعلم المنظم ذاتيا لدى طلبة

Self Regulation قسم اللغة العربية وآدابها. استخدمت الباحثات استبانة التعلم المنظم ذاتيا استبانة Miller and Brown ل Questionnaire

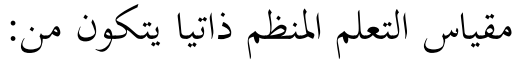




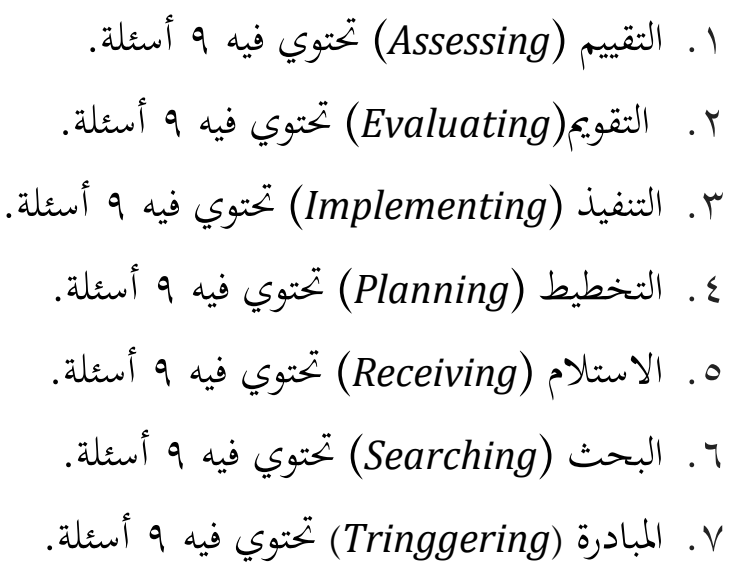

Self لنيل البيانات عن مستويات التعلم المنظم ذاتيا لدى طلبة قسم اللغة العربية وآدابها من استبانة

Miller and Brown لـ Regulation Questionnaire

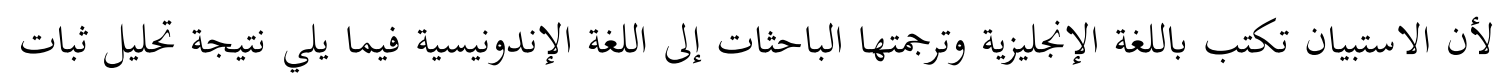
هذا الاستبيان برموز (Cronbach's Alpha) باستخدام برامج (SPSS). جدول ع : ثبات أسئلة الاستبيان (SRQ)

\begin{tabular}{cc}
\hline \multicolumn{2}{c}{ Reliability Statistics } \\
\hline Cronbach's Alpha & N of Items \\
.916 & 7r \\
\hline
\end{tabular}

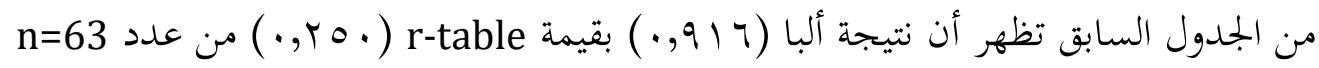
و sig =5\% ـ وبمعنى أن قيمة ألبا أكبر من قيمة r-table وهو يدل على أن أسئلة الاستبيان (SRQ) ثبات كلها.

باستخدام هذه الاستبيان عرفت الباحثات مستويات التعلم المنظم ذاتيا لدى الطلبة الجامعة الإسلامية الحكومية مالانج باعتماد على معيار النتيجة عند ميلر وبراون ، والنتيجة فيما يلي: جدول ه : مستوى التعلم المنظم ذاتيا

\begin{tabular}{|c|c|c|c|}
\hline 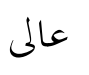 & متوسط & منحفض & مستوى التعلم المنظم ذاتيا \\
\hline$r$ & Tr & 1 & عدد الطلبة \\
\hline \multirow[t]{2}{*}{$\% \wedge$} & $\% \wedge \wedge$ & $\% \varepsilon$ & درجة مائوية \\
\hline & | & & الوسط الحسابي \\
\hline
\end{tabular}


من خلال الجدول تعرف أن مستوى التعلم المنظم ذاتيا لدى الطلبة في هذا القسم فيما يلى:

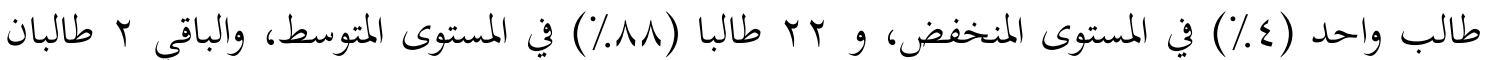

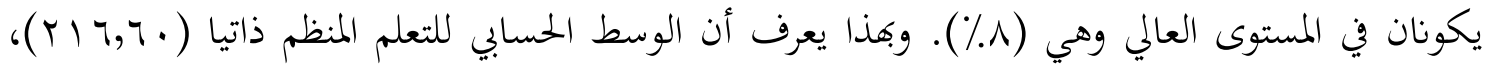

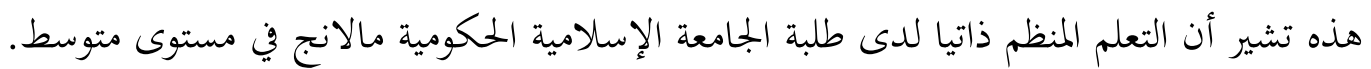

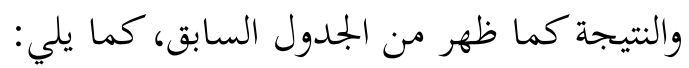

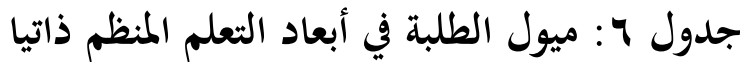

\begin{tabular}{|c|c|c|}
\hline (Cronbach's Alpha) & أبعاد التعلم المنظم ذاتيا & 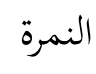 \\
\hline$\cdot, \wedge \backslash \wedge$ & التقييم (Assessing) & 1 \\
\hline$\cdot, \wedge 19$ & التقويم(Evaluating) & r \\
\hline$\cdot, \wedge \mid r$ & التنفيذ (Implementing) & r \\
\hline$\cdot, \wedge \vee \vee$ & التخطيط (Planning) & $\varepsilon$ \\
\hline$\cdot, \wedge 19$ & الاستلام (Receiving) & ○ \\
\hline., 897 & البحث (Searching) & 7 \\
\hline$\cdot, \wedge \varepsilon \varepsilon$ & المبادرة (Tringgering) & V \\
\hline
\end{tabular}

انطلاقا من الجدول السابق، يعرف أن بند الأسئلة قيمة الأهمية > مستوى الأهمية ٪\%

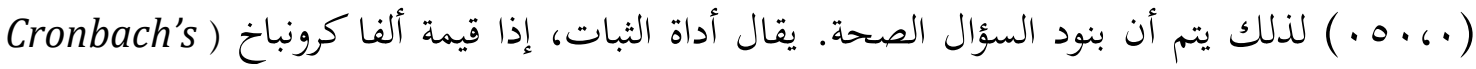

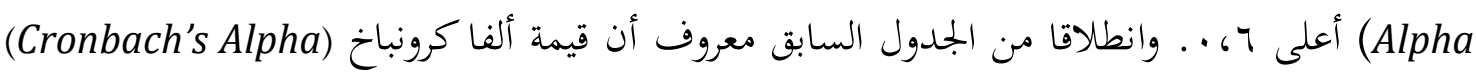
أعلى 7، . لذلك يعرف أن بنود الأسئلة الثبات. جدول V: دلالة احصائية بين التعلم المنظم ذاتيا ومهارة القراءة لدى طلاب في هذا القسم

\begin{tabular}{|c|c|c|c|}
\hline قيمة مهارة القراءة & التعلم المنظم ذاتيا & & \\
\hline *** ץ०96 & 1 & $\begin{array}{r}\text { Pearson } \\
\text { Correlation }\end{array}$ & \\
\hline, 000 & & Sig. (2-tailed) & التعلم المنظم ذاتيا \\
\hline 171 & 171 & العدد & \\
\hline \multirow[t]{2}{*}{1} & *** ץ०96 & $\begin{array}{r}\text { Pearson } \\
\text { Correlation }\end{array}$ & \\
\hline & $\cdots 6$ & Sig. (2-tailed) & قيمة مهارة القراءة \\
\hline 171 & 171 & العدد & \\
\hline
\end{tabular}


**. Correlation is significant at the $\cdot$. $)$ level (2-tailed).

rtabel $_{(0 \% ; 1 \% 1)}=\cdot 6101$

rhitung > rtable تحليل العلاقة بين التعلم المنظم ذاتيا وقيمة مهارة القراءة الحصلول

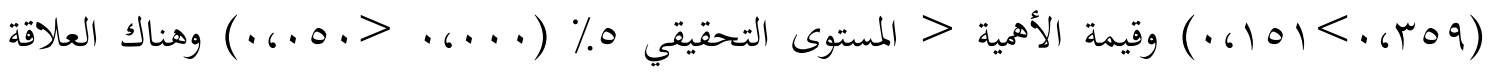
الأهمية بين التعلم المنظم ذاتيا بقيمة مهارة القراءة. معامل الارتباط الإيجابي يدل أن العلاقة بين التعلم المنظم ذاتيا وقيمة مهارة القراءة وهي في نفس الاتجاه، والمعنى كلما زادت التعلم المنظم ذاتيا فقيمة مهارة القراءة أعلى. فئة المعامل العلاقة وهب، . داخل في فئة قوية جدا. وهذا يدل إذا التعلم المنظم ذاتيا لدى طلاب اللغة العربية مرتفعة، كانت كفاءقم في مهارة القراءة عالية. H1 = هناك علاقة بين التعلم المنظم ذاتيا ومهارة

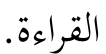

ظهرت نتائج البحث أن هناك علاقة بين التعلم المنظم ذاتيا لطلاب في قسم اللغة العربية وآدابها في هذه الجامعة وقدرقم في مهارة القراءة حيث كانت قيمة ارتباط بيرسون وهـ, . بقيمة معنوية >ه .., . هذا يدل على أن هناك علاقة بين التعلم المنظم ذاتيا وقدراتم في مهارة القراءة للطلاب بمستوى عال. وهذا أنه كلما زاد التعلم المنظم ذاتيا الطلاب، زادت قدرةم في مهارة القراءة. وفقا للبحث الذي أجرته مريم ب. مما تؤدي إلى وجود علاقة ذات دلالة إحصائية بين التعلم المنظم ذاتيا وتحصيل الطالب الأكاديمي. وأكد سفريانتو وفوسفيت بأن هناك علاقة قوية بين التعلم المنظم ذاتيا وتحصيل الطالب الأكاديمي (Supriyanto, 2015; Puspita \& Rustika, 2018 )

تتوافق نتائج هذه الدراسة مع رأي مالتي (Maltaby F. S, Gage Ni, Berliner, D, 2005) وفردوس(Firdaus et al., 2020) بأن شخص قادر على التعلم بشكل المنظم ذاتيا سيكون لديه إمكانات أكبر لتحقيق تحصيل أكاديمي عالٍ. علاوة على ذلك، أوضح الباحثون قبله أن هذا الإنجاز العالي كان بسبب حصول طلاب التعلم المنظم ذاتيا يمكنهم تحديد مشكلاتمم واختيارها بحرية وتخطيط الأنشطة واقتراح النتائج في هاية النشاط. أكد تاهار وآجيغ (Tahar, 2006) على أن الطلاب في التعلم المنظم ذاتيا يمكنهم التحكم في وعيهم الشخصي، وتنظيم دوافعهم وكفاءقم بحرية، فضلاً عن المهارات التي سيحققوها. ويؤكد هذا الرأي أنه من الضروري لدى الطلاب امتلاك المهارات الفكرية والمعرفة التي تسمح لهم باختيار وظيفتهم بفعالية وكفاءة. يمكن للطلاب التعلم من موضوع درس معين من خلال قراءة الكتب أو مشاهدة برامج الوسائط السمعية والبصرية والاستماع إليها دون مساعدة أو بمساعدة محدودة من الآخرين. 
(Latipah, 2010; M.Ed., Ph.D., Universitas Terbuka, وقالت لطيفة وأَستري بأن نتيجة هذا البحث لخاص بالطالب كان Indonesia, astri@ecampus.ut.ac.id et al., 2020) له تأثير على التحصيل الأكاديمي للطالب بالتعليم المنظم ذاتيا. هذا لأن الطلاب القادرين على الحصول على التعلم المنظم ذاتيا وطلاب يمكنهم التحكم في أنفسهم، ولديهم دوافع التعلم عالٍ، ويعتقدون أن لديهم توجهًا أو بصيرة واسعة ومرنة. عادةً ما يكون الطلاب المرنون والمستقلون وغير المطابقين قادرين على التعلم بشكل مستقل، ولكن عادةً ما تظل هناك حاجة إلى دعم المعلمين وتوجيهـهم لهؤلاء الطلاب. وبالتالي، فإن الكفاءات التي تؤدي إلى عملية التدريس والتعلم يتم تحديدها من قبل الطلاب أنفسهم. يجد الطلاب ويختارون الكفاءات التي يرغبون فيها. يمكن للطلاب التدرب على تحقيق هذه الكفاءات المطلوبة في أي وقت، لأن جميع الأنشطة التي يتم تنفيذها لم تعد أن تعتمد على مدرس أو مدرس تظهر النتائج في البحث أعلاه أيضًا أن التحصيل الدراسي يتأثر بعاملين يعنى خارجي وداخلي. وكان هذا مدعوما من قبل جوغ في سوراسا التي تنص على أن التعلم لا تتحكم فيه الجوانب الخارجية فحسب، بل تتحكم فيه أيضًا الجوانب الداخلية التي تحكمها نفسها (التعلم المنظم ذاتيا). لذلك، يجب فهم التعلم على أنه عملية نشيطة وبناءة والتعلم المنظم ذاتيا حتى يحصل الأفراد الذين يتعلمون على إنجازات أكاديمية جيدة، إذا كانوا على دراية ومسؤولين ومعرفة باستراتيجيات التعلم الفعالة أو لديهم استراتيجيات التعلم المنظم ذاتيا جيدة في التعلم المنظم ذاتيا جيد. كانت نتيجة البحث الذي أجراه وينشتاين وماير في كتابة باسوكي (Basuki, 2005) الذين وجدوا أن الأفراد الذين لديهم المنظم ذاتيا جيد في التعلم سيكونون قادرين على تمكين استراتيجيات التعلم المنظم ذاتيا المختلفة، وخاصة استراتيجيات الإدراك وما وراء المعرفة التي ستنتج تحصيلًا أكاديميًا أعلى من الأفراد غير القادرين على تمكينهم. يستخدم الأفراد ذوو المنظم ذاتيا العالي أيضًا استراتيجيات التخطيط والتنظيم والمراقبة الذاتية أكثر من الأفراد ذوي المنظم ذاتيا المنخفض(Marcou \& Philippou, 2005). ومع ذلك، في هذه الدراسة العلاقة قوية جدا في الفئة. يشير هذا إلى أن طلاب في الجامعة مولانا مالك إبراهيم الإسلامية مالانج التعلم المنظم ذاتيا لدراسة مهارة القراءة مازالوا في الفئة المتوسطة. يعتمد هذا على نتائج البحث حيث كان لدى معظم العينة المكونة من VI V طالبًا التعلم المنظم

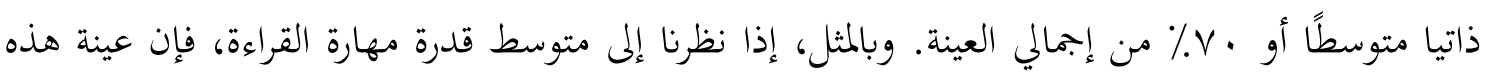

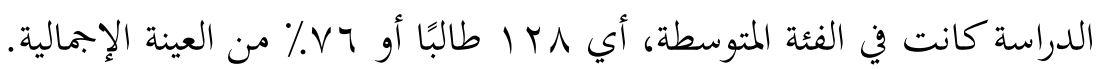
في هذه الحالة، عند النظر إليها من مفهوم التعلم المنظم ذاتيا، يمكن القول أن التعلم المنظم ذاتيا المملوكة لبعض طلاب في الجامعة مولانا مالك إبراهيم الإسلامية الحكومية مالانج المتخصصين في قسم 
اللغة العربية وآداهما هي قوة دافعة تؤثر على السلوك الذي يتخذه الأفراد لتحقيق الأهداف. نسبة صغيرة

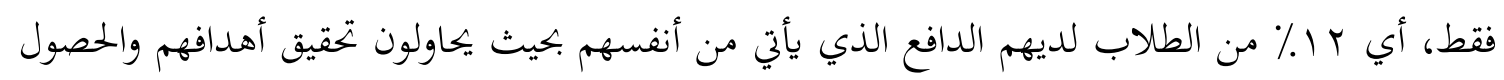

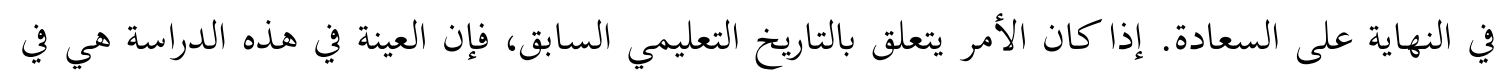

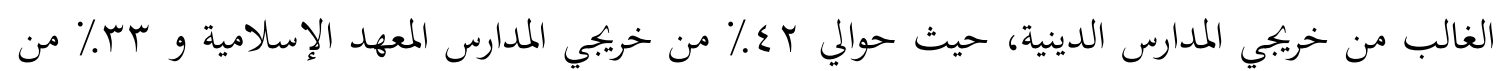

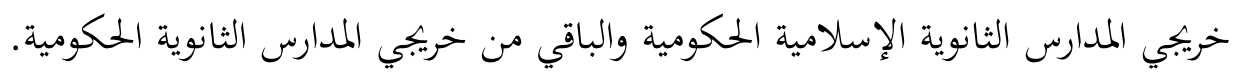

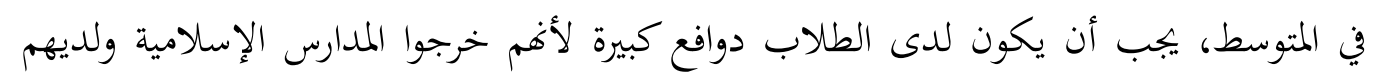

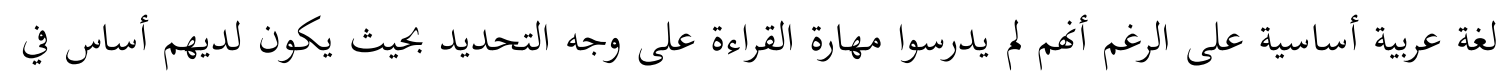

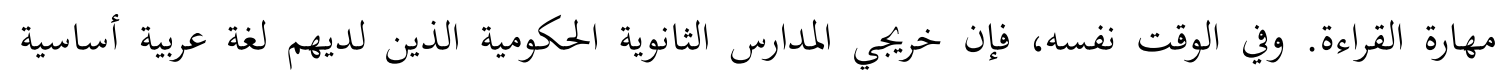

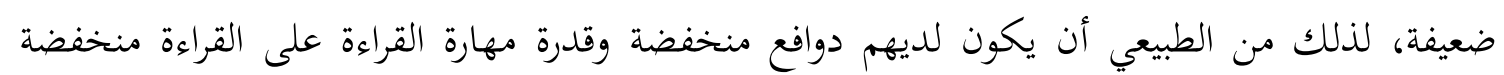
أيضًا.

إذا كان يتعلق بالمفهوم عند إيمان وطوط(Wa Akharūn, 2014) بأن التعلم المنظم ذاتيا هو أحد

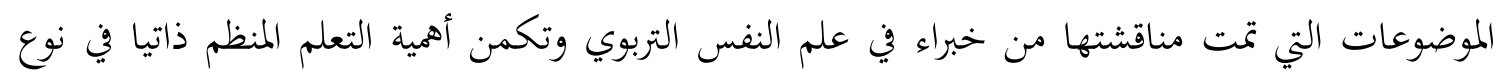

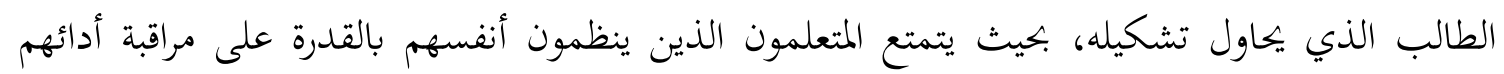
وتحديد وتنفيذ الاستراتيجيات المناسبة مدفوعة نحو التعلم.

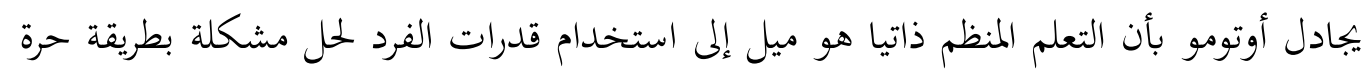

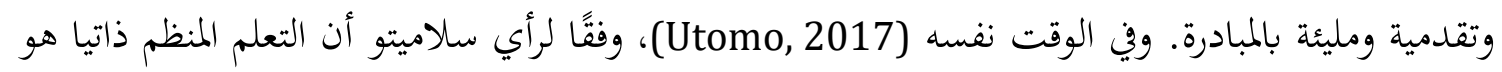
يتم التعلم بمساعدة قليلة أو بدون مساعدة من الخارج (Slameto, 2010). من الرأي أعلاه، يتم التأكيد

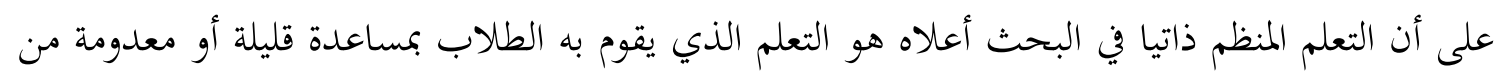

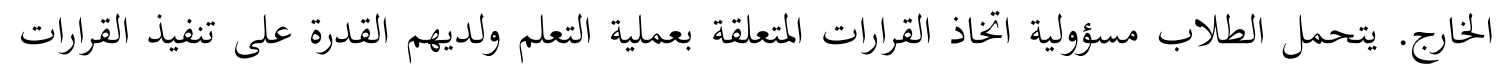

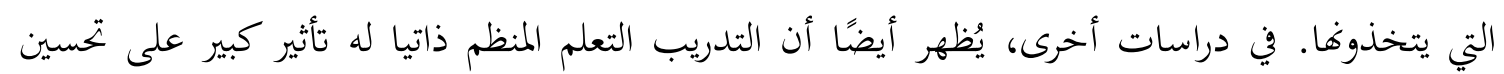
التحصيل الأكاديمي لدى الطلاب. في دراس.

وتدعم هذه نتائج الدراسة إلى نتائج البحث السابق الذي أجراه ستوغلير وزيغلير اللذان وجدا

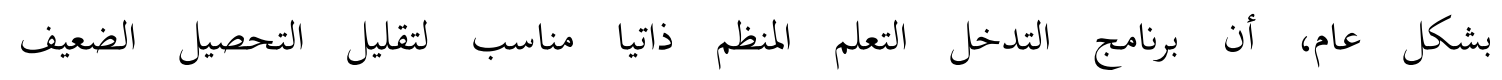
وفي النهاية يمكنه تحسين التحصيل الأكاديمي لدى طلاب المدارس الابتدائية.

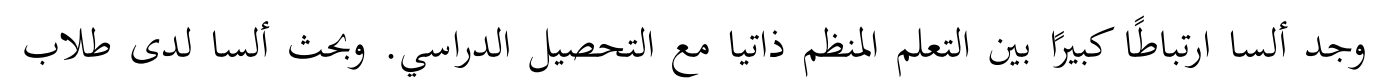

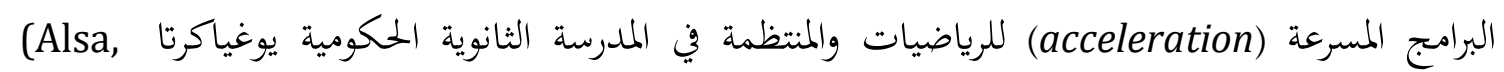

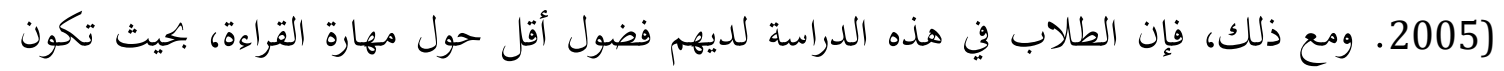


قدرة مهارة القراءة وهم في المستوى المتوسط. يمكن ملاحظة ذلك من خلال عدم قدرة الطلاب على تنظيم

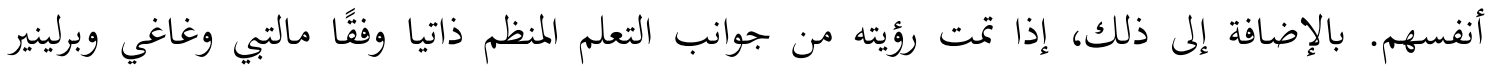
(Maltaby, F. S, Gage Ni, Berliner, D, 2005; Cheng, 2011; Olakanmi \& Gumbo, ودافيت n.d., 2017 ) يمكن لطلاب التعلم المنظم ذاتيا تحديد مشكلاقم واختيارها بحرية وتخطيط الأنشطة واقتراح النتائج في فاية النشاط.

وفي الوقت نفسه، أكد كول وإيسيف ودرميانطي أنه في التعلم المنظم ذاتيا، يمكن للطلاب

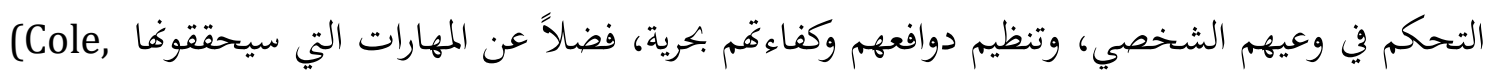

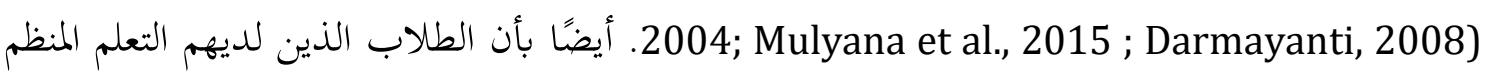

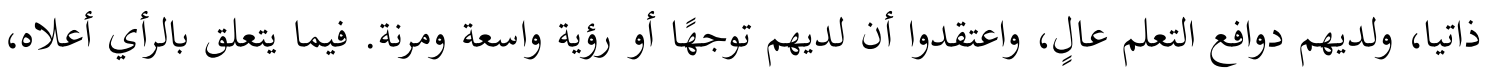

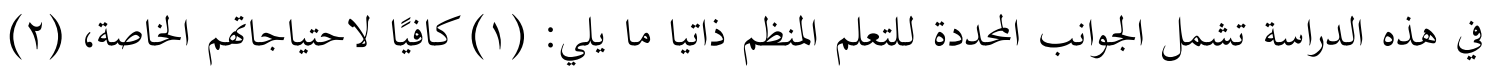
قادرة على الفعل بوظائف الروتينية، (r) القدرة على المبادرة، (ع) القدرة على حل المشكلات، (ه) واثق،

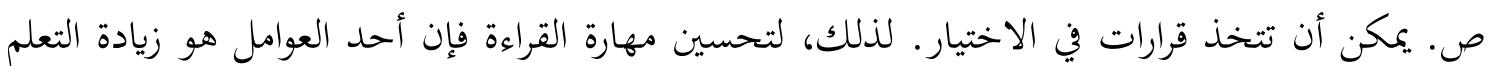
المنظم ذاتيا من خلال تكرار الدروس السابقة، وتخطيط الوقت وأهداف التعلم، وإدارة بيئة التعلم، وإعطاء

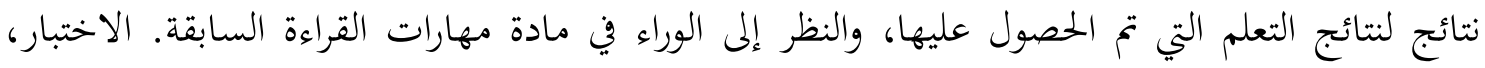
الذي يبحث عن المعلومات الصحيحة حول مهارة القرءة غير المفهومة، يمارس ويحفظ مادة مهارة القراءة،

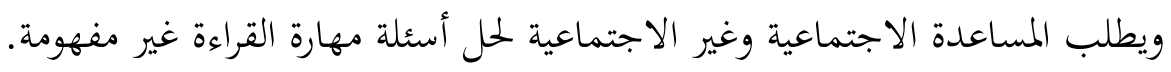

الخاتمة

وفقا على ما بحثت الباحثات من عرض البيانات وتحليلها ومناقشتها، فتخلصت نتيجة هذا rhitung > rtable البحث كالتالية: هناك العلاقة بين التعلم المنظم ذاتيا وقيمة مهارة القراءة لحصول

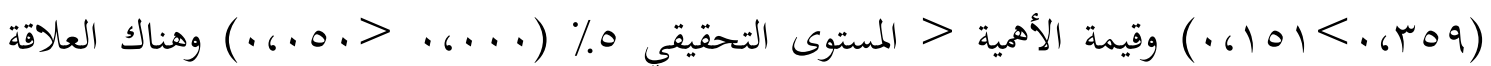
الجوهرية بين التعلم المنظم ذاتيا بقيمة مهارة القراءة. معامل الارتباط الإيجابي يدل أن العلاقة بين التعلم المنظم ذاتيا ونتيجة مهارة القراءة وهي في نفس الاتجاه، والمعنى كلما زاد التعلم المنظم ذاتيا فقيمة مهارة القراءة أعلى. فئة المعامل العلاقة Vهr، . داخل في فئة قوية جدا. وهذا يدل إذا التعلم المنظم ذاتيا لدى طلاب اللغة العربية مرتفعة، كانت كفاءقم في مهارة القراءة عالية. H = هناك علاقة بين التعلم المنظم ذاتيا بمهارة القراءة. 


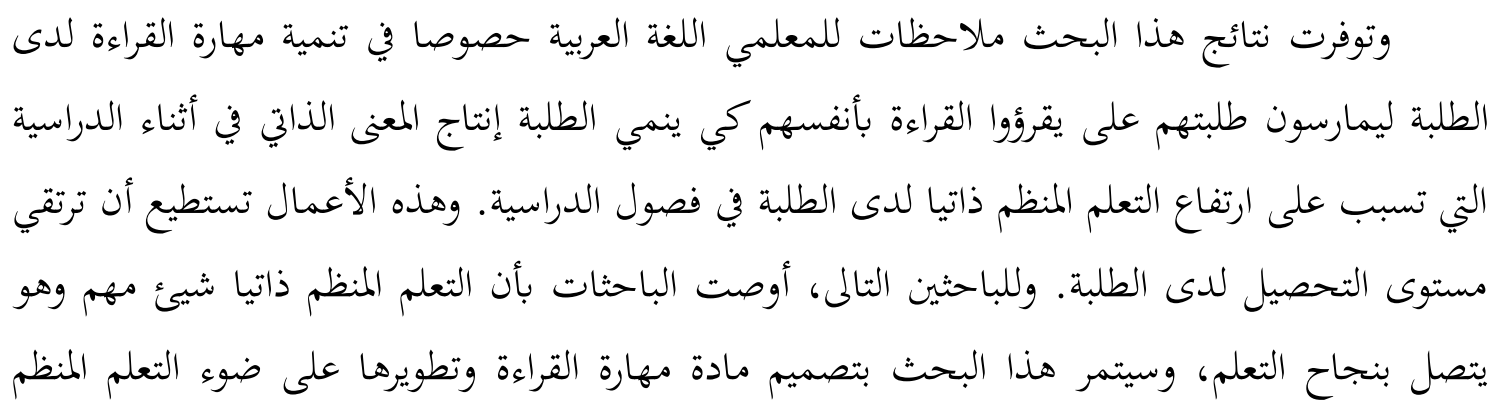

Alsa, A. (2005). Program Belajar, Jenis Kelamin, Belajar Berdasarkan Regulasi Diri dan Prestasi Belajar Matematik pada Pelajar SMUN di Yogyakarta. Universitas Gajah Mada Yogyakarta.

Basuki, A. M. H. (2005). Pengujian Kontribusi Belajar yang Bermakna pada Kreativitas, Self Regulated Learning dan Prestasi Akademik (Studi Kasus pada Siswa Sekolah Menengah Umum di Jakarta). Proceeding, Seminar Nasional PESAT'2005.

Cheng, E. C. K. (2011). The Role of Self-regulated Learning in Enhancing Learning Performance. 17.

Cole, P. G. (2004). Teaching Principles and Practice. Prestice Hall.

Darmayanti, T. (2008). Efektivitas Intervensi Keterampilan Self-Regulated Learning Dan Keteladanan Dalam Meningkatkan Kemampuan Belajar Mandiri Dan Prestasi Belajar Mahasiswa Pendidikan Jarak Jauh. Jurnal Pendidikan Terbuka Dan Jarak Jauh, 9(2), 68-82.

Deviana, A. D., Asri, F., \& Rusuly, U. (2019). Relation between Self-efficacy and Creative Thinking at Writing Skill Learning. Dinamika Ilmu, 19(2), 197-210. https://doi.org/10.21093/di.v19i2.1553

Elyana, L. (2017). Peran self regulated learning dalam pembelajaran PAUD. Temu Ilmiah X Ikatan Psikologi Perkembangan Indonesia, 59-64.

Firdaus, S., Rachman, L., \& Firmansyah, M. (2020). Analisa Faktor Pengaruh SelfRegulated Learning Terkait Performance Goals terhadap Prestasi Akademik Factor Analysis of Self-Regulated Learning Related to Performance Goals on Academic Achievement. Jurnal Kedokteran Komunitas, 8(2), 94-100.

Latipah, E. (2010). Strategi Self Regulated Learning dan Prestasi Belajar : Jurnal Psikologi, 37(1), 110-129.

MĀHIR, B., 'ABDUL. (2010). Sīkūlūjiyyah Al-Qirā'ah Wa Taṭbīqātuha. Dar AlMasīrah Li Al-Nasyar Wa Al-Tauzī'.

Maltaby, F. S, Gage Ni, Berliner, D, \& D. C. (2005). Educational Psychology, an Australia and New Zealand Perspective. Brishbane. 
Marcou, a, \& Philippou, G. (2005). Motivational beliefs, self-regulated learning and mathematical problem solving. Pme Conference, 3, 297-304.

Marlina, M. (2017). Increasing Self Regulated Learning of Students with Special Needs Through the ILBaWEL Model. Journal of ICSAR, 72-80. https://doi.org/10.17977/um005v1i12017p072

Marwān, Sy. H. W. (2012). Marwān. Sy. H. W (2012) Al-Marja' Fī Ta'līm Al-Lugah Al-Arabiyyah Wa Ta'līmiha. . Maktabah Al-Dar Al-Arabiyyah Li Al-Kitāb.

M.Ed., Ph.D., Universitas Terbuka, Indonesia, astri@ecampus.ut.ac.id, Suhandoko, A. D. J., Hsu, C.-S., \& Prof., National University of Tainan, Taiwan, shuc@mail.nutn.edu.tw. (2020). Applying Self-Regulated Learning Intervention to Enhance Students' Learning: A Quasi-Experimental Approach. International Journal of Instruction, 13(3), 649-664. https://doi.org/10.29333/iji.2020.13344a

Mulyana, E., Mujidin, M., \& Bashori, K. (2015). Peran Motivasi Belajar, Self-Efficacy, dan Dukungan Sosial Keluarga Terhadap Self-Regulated Learning pada Siswa. PSIKOPEDAGOGIA Jurnal Bimbingan Dan Konseling, 4(2), 165. https://doi.org/10.12928/psikopedagogia.v4i2.4480

Olakanmi, E. E., \& Gumbo, M. T. (n.d.). The Effects of Self-Regulated Learning Training on Students' Metacognition and Achievement in Chemistry. 15.

Pratama, F. W. (2017). Peran Self-Regulated Learning Dalam Memoderatori Pembelajaran Dengan Pendekatan Saintifik Terhadap Hasil Belajar Siswa. Satya Widya, 33(2), 99-108. https://doi.org/10.24246/j.sw.2017.v33.i2.p99-108

Puspita, S. A. L., \& Rustika, I. M. (2018). Peran Self-Regulated Learning dan Konsep Diri terhadap Prestasi Prestasi Universitas Udayana yang pernah menjadi Finalis Bali Pageant. Jurnal Psikologi Udayana, 5(1), 1-11.

Santrock, J, W. (2008). Psikologi Pendidikan. Kencana Prenada Media.

Slameto. (2010). Belajar dan Faktor-faktor yang Mempengaruhinya. Jakarta: Rineka Cipta. Rineka Cipta.

Supriyanto. (2015). Hubungan Antara Self-Regulated Learning dan Prestasi Akademik pada Mahasiswa Semester Pertama Prodi Psikologi Universitas Pembangunan Jaya. Jurnal Universitas Pembangunan Jaya, 2, 1-27.

Sutikno. (2015). Pengaruh Strategi Pembelajaran Mandiri, Self Regulated Learning, dan Motivasi Berprestasi terhadap asil Belajar Praktik Produktif Peserta Didik di SMK. Pascasarjana Universitas Negeri Malang.

Tahar, I. (2006). Hubungan Kemandirian Belajar Dan Hasil Belajar Pada Pendidikan Jarak Jauh. Jurnal Pendidikan Terbuka Dan Jarak Jauh, 7(2), 91101.

Utomo, J. (2017). Membangun Harga Diri. Jakarta: Gramedia. Gramedia. 
Wa Akharūn, I. W. (2014). Simmah Al-Tafāul Wa Al-Tasyāum Wa Alāqatuha Bi AlDāfi' Al-Muta'llim Ladā 'Ainah Min Țalabah Al-Bakālūiyyā [PhD Thesis]. Risālah Li Sanās Gair Mansyūr Al-Jarā'ir.

Yulanda, N. (2017). Pentingnya Self Regulated Learning Bagi Peserta Didik Dalam Penggunaan Gadget. Research and Development Journal of Education, 3(2), 164-171. https://doi.org/10.30998/rdje.v3i2.2013

Zahary, M. (2015). Meningkatkan Prestasi Belajar Matematika Siswa Melalui Strategi Self Regulated Learning. Seminar Nasional Matematika Dan Pendidikan Matematika Uny, 24(Pasal 3), 163-168.

Zimmerman, B. J. (2002). Becoming a Self-Regulated Learner An Overview. Collage of Education, The Ohio State University, 41(2), 64-70.

Zimmerman, B. J., \& Martinez-Pons, M. (1990). Student differences in self-regulated learning: Relating grade, sex, and giftedness to self-efficacy and strategy use. Journal of Educational Psychology, 82(1), 51-59. https://doi.org/10.1037//0022-0663.82.1.51

\section{COPYRIGHT NOTICE}

Authors retain copyright and grant the journal right of first publication with the work simultaneously licensed under a Creative Commons Attribution 4.0 International License that allows others to share the work with an acknowledgement of the work's authorship and initial publication in this journal. 